\title{
Hermenêutica botânica e antropização na Amazônia: Exsicatas de Verbenáceas da Amazônia Legal no Herbário do New York Botanical Garden
}

\section{Botanical hermeneutic and anthropization in the Amazon: Exsicatas of Verbenaceae from the Brazilian Amazon in the New York Botanical Garden Herbarium}

Gutemberg Armando Diniz Guerra - Doutor em Socioeconomia do Desenvolvimento pela École des Hautes Études en Sciences Sociales, Paris, França. Professor Associado - Núcleo de Ciências Agrárias e Desenvolvimento Rural da Universidade Federal do Pará. E-mail: gguerra@ufpa.br

Maria de Naz̧aré Angelo Menezes - Doutora em História Agrária pela École des Hautes Études en Sciences Sociales, Paris, França. Professora Associada - Núcleo de Ciências Agrárias e Desenvolvimento Rural da Universidade Federal do Pará. E-mail: mnam@ufpa.br

Lin Chau Ming - Doutor em Botânica, Instituto de Biociências - Botucatu (1996) e Doutor em Agronomia, Faculdade de Ciências Agronômicas e Veterinárias - Jaboticabal (1995), Universidade Estadual Paulista Júlio de Mesquita Filho. Professor Titular da Faculdade de Ciências Agronômicas, Botucatu, da Universidade Estadual Paulista Júlio de Mesquita Filho. E-mail: linming@fca.unesp.br

\section{Resumo}

Este artigo tem como base informações de uma série histórica de exsicatas datadas de 1819 a 2002, reunindo contribuições de pesquisadores de instituições governamentais e não governamentais das Américas do Norte, do Sul e Europa. Tem foco nas verbenáceas, pela reconhecida gama de espécies aromáticas e medicinais desta família e o seu reconhecido uso no Brasil. Analisa notas descritivas e críticas sobre a coleção do New York Botanical Garden referente à Amazônia, revelando o espírito da cooperação entre instituições brasileiras e estrangeiras nesta região. Alterações do meio ambiente, rede de pesquisadores, mudanças na linguagem, na tecnologia dos registros e absorção de termos regionais são detectados ao longo de quase dois séculos de trabalho científico em que se projeta a formação continuada de cientistas e a interação com saberes locais.

\section{Palavras-chave}

Intercâmbio científico. Botânica. Exsicatas. Taxonomia. Expedições. Fotografia.

\begin{abstract}
This article is based on information from a historical series of dried herbarium specimens dating from 1819 to 2002, bringing together contributions from researchers in both governmental and nongovernmental organizations from North and South America as well as from Europe. The focus is on Verbenaceae by its recognized range of aromatic and medicinal species of this family and its recognized use in Brazil. The study examines descriptive and critical notes from the New York Botanical Garden collection relating to the Amazonia, revealing the spirit of cooperation between Brazilian and foreign institutions in this region. Changes in the environment, network of researchers, changes in the language system, technology records and absorption of regional terms are detected over almost two centuries of scientific work that projects the continued training of scientists with local knowledge and interaction.
\end{abstract}

\section{Keywords}

Scientific interchange. Botanic. Herbarium specimens. Taxonomy. Expedition. Photography. 


\section{GARIMPANDO NAS EXSICATAS}

Este trabalho foi realizado a partir da coleção de exsicatas encontradas no Herbário do New York Botanical Garden (NYBG), nos Estados Unidos. Para efeito de se obter um registro sistemático e acessível ao procedimento de análise qualificada, fotografou-se todas as exsicatas de Verbenáceas coletadas na América do Sul constantes do acervo, somando mais de 29 mil imagens. A escolha por esta família estava associada a uma indagação sobre que tipo de informações poderiam ter sido registradas sobre plantas aromáticas e medicinais consagradas pelo uso na Amazônia. Sabe-se que houve modificações na classificação desta família, incorporando as lamiáceas, mas seguimos o levantamento da maneira que ainda se encontra organizado no NYBG. O recorte geográfico foi dado pelo interesse dos autores, todos envolvidos em pesquisas sobre agricultura familiar e comunidades tradicionais na Amazônia. O objetivo original era de se verificar ocorrências, localizações das coletas, coletores, instituições financiadoras e beneficiárias do esforço de levantamento sobre esta família. As primeiras observações oportunizaram um diálogo inicial entre os pesquisadores, inspirando indagações, permitindo a elaboração de hipóteses, comentários e críticas suscitadas a partir deste esforço, tanto a respeito do material existente, quanto da metodologia proposta.

Fotografar todas as exsicatas desta família presentes no herbário e listar as informações nelas contidas foi o procedimento que se demonstrou o mais operacional, uma vez que permitiria a volta, sempre que possível, ao acervo digital construído, reservando-se para casos específicos as possibilidades de volta ao acervo original como em casos em que a verificação direta tenha-se revelado indispensável. Esta volta ao acervo original ocorreu, de fato, no caso de fotografias com problemas de visualização, dúvidas sobre dados, cortes de informações ou checagens sobre o material identificado. $\mathrm{O}$ tratamento seguinte foi o de digitação de todos os dados registrados nas exsicatas: nome científico e vulgar, país, estado, local e data da coleta, nome do coletor e identificador, patrocinadores das expedições, herbários destino das exsicatas colhidas e observações feitas pelos coletores, verificadores, identificadores e classificadores sobre as plantas e locais onde foram coletadas. Construiu-se, desta forma, um quadro geral sobre as coletas e a qualidade das informações nelas contidas.

A observação de cada exsicata permitiu inferir sobre o local da coleta no momento em que foi feita, a percepção do coletor sobre o ambiente e ocorrências históricas e contigenciais tanto na área de coleta quanto no quadro da ciência. A comparação entre os registros permitiu inferir o grau de precisão e rigor dos observadores, suscintando interrogações sobre o que teria favorecido a maior ou menor acuidade no registro. 
A diversidade na qualidade do registro é notável. Foram encontradas exsicatas com pouquíssimas informações, por vezes restritas apenas ao país da coleta. Outras contêm informações precisas, indicando local da coleta com detalhes de referenciamento geográfico, descrição das condições locais, acesso, tipo e porte da planta, croqui, mapa de localização da coleta e situação a que está submetido este local, coletor, identificador e instituição. Estas diferenças demonstram a heterogeneidade de formações, objetivos, percepções dos coletores e dos recursos empregados nas expedições, assim como uma evolução deste procedimento.

Determinadas exsicatas podem ser associadas a verdadeiras páginas de caderno de campo, pela riqueza de detalhes e observações. Outras, embora lacônicas e sintéticas, sugerem ter o coletor se reservado a observações que levam a se especular sobre possíveis cadernos de anotações, memórias, crônicas, agendas e relatórios ${ }^{1}$ que possam revelar mais detalhes sobre as excursões.

Verifica-se que informações foram adicionadas pelos identificadores ou estudiosos a posteriori da coleta, no laboratório, o que, se por um lado enriquece o material, por outro demonstra a sua fragilidade/vulnerabilidade em termos de intervenções, modificando o registro original - para melhor ou para pior.

É possível verificar que alguns dos coletores não se deram conta da importância de registros aparentemente simples, como o fato de estarem fazendo a coleta em uma mata primária ou secundária, nativa ou material cultivado, registrando assim o grau de alteração do ambiente. Isso se evidencia principalmente quando se faz referência à abertura de estradas, mineração ou atividades econômicas recém-instaladas. Alguns registram esses acontecimentos como distúrbios, pela constatação do uso de métodos como o fogo, por exemplo, tornando-se rico material de informação sobre o processo de antropização do meio ambiente ${ }^{2} \mathrm{e}$ da percepção sobre esta intervenção.

\section{FOTOGRAFIAS E REGISTROS}

O uso da técnica da fotografia como registro de informações científicas não é, em si mesma, nenhuma inovação no campo da Botânica, tendo sido observada como instrumento utilizado por pesquisadores envolvidos na construção e guarda

1 No caso de Adolpho Ducke, os seus relatórios muito esclarecem a respeito de suas incursões na Amazônia (DUCKE, 1934 e 1938).

2 BR 226 Fazenda Coco. $70 \mathrm{~km}$ E of Barra do Corda on BR 226. Disturbed forest dominated by leguminous trees. $5^{\circ} 20^{\prime} \mathrm{S}, 44^{\circ} 43^{\prime} \mathrm{W}$. Herb. $20 \mathrm{~cm}$. Corolla blue. In burned open area (D. C. Daly; D. G. Campbell; A. S. Silva; R. P. Bahia; M. R. dos Santos. No. D587, coletado em Barra do Corda no Maranhão em 11/10/1980). 
de material botânico ao longo do século XX, e em trabalhos mais recentes, para estudar as citações de uso das plantas, como os que foram realizados por Siri von Reis e Frank J. Lipp Jr., no herbário do Jardim Botânico de Nova York. Exsicatas antigas, de valor histórico, por terem sido coletadas e organizadas por personagens reconhecidos no mundo científico, como Linaeus, Martius e Spix, Poeppig e Spruce, têm sido fotografadas, enviadas para acervos de importantes instituições de pesquisa e divulgadas em livros sobre o assunto. No NYBG podese encontrar muitas delas compondo o acervo, desde meados do século XX, encontrando-se os créditos dos fotógrafos ou laboratórios responsáveis pelo trabalho nesta modalidade, constituindo-se em uma especialidade neste domínio. É o caso da exsicata de Martius, coletada no estado do Pará, em setembro de 1819, cuja fotografia do cotipo foi efetuada e enviada para o NYBG, dando conta do registro de que o tipo original se encontra no Museu de Munique, na Alemanha. Foram utilizadas informações de fotografia de exsicata $n^{\circ}$. 2114, do Museu de Viena, coletada por Richard Spruce em 1852, no estado do Amazonas. Neste caso, a fotografia foi montada pela Rockfeller Foundation Fund for Photographing Type Specimens e utilizada por Moldenke, em 1948, para publicação em sua monografia sobre gêneros. Para continuar ilustrando esta metodologia, uma exsicata coletada no estado do Pará por Emílio Goeldi, em 14 de março de 1907, isotipo do acervo do Field Museum of Chicago foi fotografado por Dahlgren, em 1929, e analisado por Moldenke, em maio de 1934.

Harold Norman Moldenke (1909-1996), responsável durante mais de 50 anos por registros desta natureza, e um dos nomes mais frequentes entre os identificadores de Verbenáceas e Lamiáceas no arquivo do NYBG, referência sobre esta família botânica, utilizou este recurso em suas viagens científicas a instituições europeias na década de 30 do século passado, conforme se pode atestar no próprio material consultado durante esta pesquisa ${ }^{3}$. No caso específico deste trabalho, as fotografias foram feitas pelos autores do artigo, sendo depois por eles transcritos para posterior tabulação e contagem. Houve problemas principalmente no que se refere às fotografias de exsicatas arquivadas como se fossem exemplares de material original. São fotografias de museus europeus, em tamanhos variados, sendo mais frequentes em $7 \times 10 \mathrm{~cm}$, com grau de definição nem sempre suficiente para leitura

\footnotetext{
Em exsicata de Citharexylum flexuosum (Ruiz \& Pav.), sem número e sem referência de onde teria sido coletada, atribuída a Humboldt e Bonpland do H. B. K Herbarium em Paris lê-se a informação de que E. T. e H. N. Moldenke fotografaram o exemplar em 1936, na Europa. Existem fragmentos de outros herbários que remontam ao início do século XX como o da coleta feita de Citharexylum cinereum L. por Ule, em maio de 1901, no estado do Amazonas, conservados no Herbário do Museu de Genebra, classificado por H. N. Moldenke, no inverno de 1930-1931.
} 
das informações constantes no original, devendo-se contentar com as transcrições feitas pelos responsáveis pela montagem. Para ilustrar, pode-se conferir a exsicata n. 2270, de Aegephila intermedia Moldenke, coletada em 11/06/1909, por Emílio Goeldi, em São Luís do Maranhão, contando com especimens nos acervos do The United States National Herbarium (tipo) e no Conservatoire et Jardin Botaniques, em Genebra (Isotipo).

Além do número elevado de material a ser tratado, um dos problemas efetivos foi a diversidade de notações dos nomes dos coletores, gerando dúvidas sobre o número exato de autores e de instituições participantes. Nos casos em que as evidências demonstravam tratar-se da mesma pessoa ou mesma instituição, elas foram agregadas. Em vários casos, os nomes eram indicados, ora por iniciais dos primeiros nomes seguidos dos sobrenomes, ora pelo nome completo. No caso de nomes de pessoas, essa tarefa foi mais difícil pelo fato de ser em maior número e de haver a possibilidade de pessoas diferentes serem portadoras do mesmo nome. De qualquer maneira, chegou-se a valores nominais e estatísticos que dão uma ideia clara do esforço fenomenal que se desprendeu para que se chegasse a coleções de tais qualidades e portes.

\section{O QUE CONSTA NOS REGISTROS DAS EXSICATAS LEVANTADAS}

Ler as exsicatas considerando todos os aspectos que nelas vêm registrados possibilita muito mais do que a percepção de aspectos botânicos, para os quais, em princípio, elas teriam sido coletadas, constituindo-se o processo de leitura, ele mesmo, um enriquecedor exercício de compreensão sobre o período que cobrem. Normalmente a leitura das exsicatas é feita individualmente, verificando-se uma por uma, o que pode oferecer informações sobre a espécie, variedade, aspectos botânicos da planta e ambiente em que foi coletada. O número variado de coletas de uma mesma espécie possibilita diferentes percepções, dependendo da época da coleta, partes da planta coletada, locais de coleta, qualidade da conservação do material coletado e das anotações feitas sobre ele e outros aspectos. Neste sentido, o que se está introduzindo neste texto é uma perspectiva de leitura das exsicatas, reconhecendo a riqueza contida não apenas nas palavras com as quais se registrou cada um dos seus aspectos, mas do significado de cada uma das informações ali presentes nas palavras e nas entrelinhas. Avança-se na perspectiva de leitura do universo de registros e das possíveis comparações entre exsicatas e dos aspectos que se modificaram ao longo do tempo contido nos registros. 
É esta perspectiva que faz evocar o conceito de Hermenêutica, como parte da filosofia voltada para a interpretação de textos consagrados, entendendo-se, neste caso, as exsicatas como texto, o que, de fato, o são (KURY, 2001). Por terem sido elaboradas por taxonomistas, aparentemente podem ter limitado os registros aos aspectos identificatórios e classificatórios das espécies estudadas, embora a contextualização em que cada uma das plantas tenha sido coletada abre a perspectiva para uma jurisdição interpretativa mais ampla do que a pretendida original e objetivamente pelos taxonomistas.

A leitura de uma série histórica, como é a proposta deste trabalho, permite uma perspectiva temporal abrangente, além dos aspectos relativos às transformações ambientais sofridas pelas áreas de coleta. Tabulados os dados existentes nas exsicatas, deu-se prioridade aos registros dos nomes científicos dos gêneros, espécies e variedades, com as variações registradas ao longo do tempo, pelos procedimentos escritos pelos botânicos que as manipularam. Primeiramente, o nome do gênero e espécie são registrados como indicativo, ainda no terreno e campo de trabalho. Examinado o material em laboratório, o botânico, com instrumental adequado, confirma, reclassifica, identifica gêneros, espécies e variedades, adicionando-se à exsicata a informação apurada com o nome e data do verificador e identificador da amostra.

Isoladas, as exsicatas se constituem em peças limitadas, mas no conjunto e em séries oferecem a possibilidade de uma interpretação dos avanços e informações temporais de significado histórico preciso. Nelas, pode-se verificar desde os avanços na tecnologia contida no material utilizado para a escrita, o que vai do lápis, passando pela pena, caneta de tinta, caneta esferográfica, máquina de escrever, impressora matricial e a jato de tinta, até a evolução do locus das coletas.

Existem fichas impressas em empresas gráficas ou em computadores para facilitar e padronizar o trabalho dos coletores, revelando igualmente o grau de esforço e rigor das equipes na uniformização do trabalho de catalogação. Constam cabeçalho com nome das instituições promotoras e nomes dos programas ou expedições e rodapé com os nomes dos herbários receptores e/ou o tipo de participação dos financiadores. Em algumas constam miniatura de croquis de localização da área da coleta. Estes recursos indicam o grau de aprimoramento que os coletores e montadores das exsicatas realizaram para que as informações pudessem ser recuperadas com a maior precisão possível, em particular se houvesse a necessidade de volta ao local de coleta.

No universo de 752, foram encontradas 13 exsicatas sem data, o que obrigou a manutenção do registro, em função das outras informações nelas contidas. Esta imprecisão quanto a este dado ocorreu em 10 casos em que a exsicata era a 
fotografia de exemplar existente em outras coleções, demonstrando igualmente a precariedade do recurso fotográfico, neste caso, incapaz de fixar a imagem com suficiente definição. Em outra, trata-se de fragmentos de exsicatas guardados, mas sem se ter exatidão da data de coleta. As duas restantes estão com as informações ilegíveis.

O período coberto pelas coletas feitas sobre as Verbenáceas na Amazônia se inicia em setembro de 1819, de uma Aegiphila filipes Mart., em local definido como verdadeira floresta amazônica, no estado do Pará, por Martius. A data registrada está compreendida no período em que ele teria expedicionado pelo Brasil (1817 a 1820), sob os auspícios da família real austríaca, a quem veio se integrar como membro da comissão científica, quando da chegada de D. Leopoldina para se tornar esposa do imperador do Brasil. Sua chegada em Belém foi a 16 de agosto de 1819, adentrando-se em seguida rio Amazonas acima.

A segunda das exsicatas mais antigas, de Amasonia erecta L. foi coletada no Mato Grosso, em Cuiabá, igualmente por Martius, sob o nº. 583, data de setembro de 1839, levantando a primeira dúvida e hipóteses sobre os registros e a data do procedimento de coleta. A data indicada corresponde efetivamente à coleta feita por algum colaborador ou à montagem da exsicata, aposterior? Martius teria recebido a exsicata de colaboradores e atribuído a si responsabilidade da montagem, favorecendo a dúvida e imprecisão sobre a data? A primeira hipótese é mais plausível, uma vez que possivelmente o tratamento e montagem de todo o material coletado tenha se dado ao longo da vida dos naturalistas, em ambiente confortável e com recursos que permitissem juntar todos os dados recolhidos, de forma a uma exposição mais adequada. O mesmo ocorreu com a coleta feita por Poeppig, com Citharexylum poeppigii Walp, sob o nº. 2910, originária de Ega, no estado do Amazonas, datada de 1845. Sabe-se que a viagem de Poeppig pela América do Sul ocorreu entre 1826 e 1832, deixando, portanto, a amostra fora da possibilidade de ter sido feita por ele mesmo ou, seguindo a mesma linha adotada para a interpretação sobre a segunda amostra de Martius, ele teria montado a exsicata anos depois, na Europa.

Estes são dois indicadores das possibilidades de leitura registrados neste rico material da coleção do New York Botanical Garden.

Tomando os dados de frequência das coletas, demonstra-se a intensidade dos procedimentos de construção deste acervo.

A ocorrência de coletas de Verbenáceas na Amazônia Brasileira entre 1819 e 2002 indica os períodos de pico nos anos 1970 a 1987, com a maior pontuação no ano de 1980, com 66 amostras. Atividades realizadas em cooperação internacional estão documentadas desde o início do século XIX, como demonstra a presença 
de Henry Hurd Rusby e outros na Amazônia, no esforço de catalogar a flora deste bioma (UYTERHOEVEN, 2008). Neste mister, deve-se considerar a existência do Programa Flora, em que o Projeto Flora Amazônica se enquadrava. Vigorando nas décadas de 70 e 80 do século XX, foi um dos maiores esforços articulados entre instituições brasileiras e internacionais para repertoriar a flora brasileira, e, no caso do Projeto específico para a Amazônia, fica demonstrada a sua intensidade (DALY; LISBOA, 1991). Envolvendo instituições governamentais e não governamentais, Programa e Projeto são uma demonstração cabal do que podem fazer equipes associadas de cooperação local, nacional e internacional, no que concerne ao repertório da biodiversidade.

Deve-se considerar, em detalhe, a participação dos botânicos no processo de organização da coleção, o que vem registrado nas exsicatas em distintas fases, como coleta, identificação, verificação e classificação ou confirmação do trabalho realizado pelo coletor. Neste particular, é marcante a presença de Harold Norman Moldenke, que aparece fazendo verificações em Verbenáceas durante um período de 55 anos, entre 1929 e 1984, no Jardim Botânico de Nova York, conforme os dados demonstram. Segundo a biografia disponível no site do NYBG, ele começa os seus trabalhos naquele ano de 1929, como pesquisador associado, em tempo parcial. Galgou diversos postos de comando do NYBG, até o seu falecimento em 1996. É possível que o período de trabalho dele tenha sido mais extenso do que o que se pode apreender pelo material utilizado neste artigo, restrito a uma única família botânica, da qual se torna referência. Deduz-se que era dedicado ao trabalho na instituição, embora seu desempenho fosse visto com crítica pelos botânicos. Segundo G. T. Prance, Moldenke era especialista em Verbenáceas, mas promoveu excessiva segmentação sistemática das famílias vegetais nas classificações que operacionalizou ${ }^{4}$.

É de Eduard Friedrich Poeppig a terceira mais antiga exsicata, datada de 1845, sem registro de dia e mês da coleta. Nascido em Plauen, na Saxonia, a 16 de julho de 1798 e falecido em Wahren, perto de Leipzig, em 4 de setembro de 1868, este zoólogo e naturalista alemão viajou pela América do Sul entre 1826 e 1832, tendo contribuído com a descrição de mais de 4.000 tipos de plantas. Percorreu todos os $5.000 \mathrm{~km}$ de extensão do rio Amazonas, constituindo-se em um dos pioneiros da exploração desta região.

Richard Spruce ${ }^{5}$, considerado um dos mais importantes nomes da botânica internacional, segue a lista dos pioneiros. Sua passagem em Santarém ocorre em

4 Comentário feito no Herbário do New York Botanical Garden, dia 28/02/2009, para os autores.

5 Nasceu em Ganthorpe, Yorkshire, 10 de setembro de 1817 e morreu em Castle Howard, Yorkshire, 28 de dezembro de 1893, foi médico e naturalista britânico. 
1850, no segundo ano de sua longa viagem pela América do Sul (1849-1864) e assume importância pelo reconhecimento do elevado grau de percepção e qualidade dos registros que fez em suas viagens de campo. Escritas em latim, as notas contidas na exsicata são breves, mas precisas, tanto quanto se praticava na época (In vicinibus Santarém). Das 13 exsicatas coletadas por Spruce, dos gêneros Aegiphyla, Amasonia, Vitex, Citharexylum, seis estão apresentadas sob forma de fotografias de tipos e isotipos do Royal Botanic Garden, Kew; do Botanisches Museum, Berlim, do Herbier Boissier, Genebra e do Herbário de Viena. Juntamente com sete exsicatas montadas de material primário, cobrem um período de quatro anos, entre 1850 e 1853.

Um demarcador interessante de gerações de botânicos é a alternância na predominância no uso das línguas nas exsicatas. O latim, entre os mais antigos, vai desde 1819 até 1942, ou seja, de Martius até Ducke. Embora houvesse a predominância do latim, encontram-se amostras com anotações em português, inglês e alemão, obedecendo, entretanto, a mesma sistemática nas anotações. $\mathrm{O}$ inglês passa a predominar a partir de 1930 e vem permanecendo, embora sejam crescentes as anotações feitas em português, dividindo ou indicando a parceria americano-brasileira nesta atividade.

\section{QUEM REALIZOU AS COLETAS?}

Além dos coletores considerados históricos e destacados no item sobre o período das coletas, os registros variam na precisão sobre estes personagens, embora este seja um dado que apresenta alta confiabilidade pelo fato de ter sempre pelo menos um nome assumindo a responsabilidade da coleta, e de estas pessoas serem muito conhecidas na área de domínio da taxonomia botânica. Em muitos casos, principalmente os mais recentes, verifica-se o registro de toda a equipe, envolvendo até uma dezena de participantes, desde profissionais reconhecidos até profissionais e estudantes em processo de formação e aperfeiçoamento. Quando se tratou deste registro coletivo, considerou-se como principal coletor o primeiro nome da lista, conforme a tradição na área de conhecimento. Nas exsicatas mais antigas este registro é mais frequente com a presença de apenas um nome, ficando a dúvida se o botânico fazia o seu trabalho isolado, o que não raro acontecia, pela escassez de mão de obra especializada, ou se ele assinava material preparado por outros sob sua orientação e subordinação, pela prática naqueles contextos específicos. Pode ter ocorrido o fato de, embora fazendo o trabalho em equipe, assumir a responsabilidade do registro com o seu único nome. 
Verificou-se que no caso de registros da equipe existem nomes de conhecidos botânicos que aparecem liderando os grupos. Outros nomes aparecem apenas constando nas equipes, sem jamais aparecerem em primeiro lugar. Sabese, pela prática, que em alguns destes casos tratam-se de estudantes, aprendizes, mateiros ${ }^{6}$ ou funcionários dos institutos de pesquisa envolvidos nesta atividade durante décadas, fazendo-se reconhecer pelo conhecimento empírico aprofundado na prática de anos a fio, no desempenho da função de apoio às expedições. Em geral, são pessoas muito importantes no processo de coleta, pelas informações que pode agregar em termos de um conhecimento prático e uso cotidiano, que favorecem o processo de classificação.

O processo de coleta é um dos passos importantes na identificação de novas plantas, podendo levar muitos anos de elaboração a partir da exsicata. É o que se pode concluir do texto de Aymard e Cuello (2004), que cita a coleta feita por I. Cordeiro, em 1985, permitindo a identificação da Aegiphila aracaensis no Brasil.

Aegiphila aracaensis Aymard \& Cuello, sp. nov. TYPE: Brazil. Amazonas: Barcelos, rio Aracá, próximo a foz do Rio Jauari, 008309N, 638309W, 4 July 1985, I. Cordeiro 150 (holotype, MG; isotypes, NY, US). Figure 1.

Demonstrou-se no levantamento a possibilidade de varredura extensiva tanto no tempo quanto no espaço, quando se estabeleceram cooperações entre instituições locais e internacionais, no sentido mais amplo. Deparou-se, durante a triagem e análise das exsicatas, com universo amplo de exemplares coletados e registrados em todos os países da América do Sul tanto por pesquisadores e instituições do mesmo continente de origem da amostra quanto de países como os Estados Unidos, e europeus como a França, Inglaterra, Áustria e Alemanha. O processo de retroalimentação pelas coletas e acesso aos arquivos que armazenam as informações dinamiza a atividade científica e estimula os seus participantes.

Para efeito desta análise, a importância do registro ganha densidade pela demonstração do esforço numérico de pessoas que esta atividade mobiliza, exigindo competência específica. Foram anotadas 396 pessoas envolvidas no processo de coleta, sejam como principais responsáveis, sejam fazendo parte de equipes. Entre os principais, foram enumerados 164 nomes assumindo esta posição. Ghilean Tolmie Prance ${ }^{7}$ ocupa o primeiro lugar, com 73 ocorrências como coordenador de equipe ou como primeiro nome na lista de coletores nas fichas apresentadas.

$6 \quad$ Trabalhador de origem nativa ou morador radicado há muito tempo na região de estudo, ou funcionário antigo da instituição de pesquisa, acostumado à identificação de plantas e animais, utilizados nas expedições como guias e informantes.

Ghillean Tolmie Prance é inglês, nascido em 1937, com atividade destacada principalmente no período mais intenso do Programa Flora. 
O segundo nome mais incidente é o de João Murça Pires, 46 vezes citado como coletor principal, seguido de C. A. Cid/C. A. Cid Ferreira, com 29 coletas; Douglas C. Daly, N. A. Rosa, Nilo T. da Silva e Ricardo de Lemos Fróes, cada um com 21 coletas; Adolpho Ducke, com 20 coletas; B. A. Krukoff, com 19 coletas e G. A. Black, com 17 amostras coletadas. Verifica-se entre estes dez a presença de angloamericanos e brasileiros liderando a lista, conforme se demonstra na Tabela 1.

Tabela 1. Frequência dos 10 coletores principais mais frequentes.

\begin{tabular}{l|c|c|c|c}
\hline \multicolumn{1}{c|}{ Coletor principal } & $\begin{array}{c}\text { Frequência } \\
\text { como primeiro } \\
\text { nome }\end{array}$ & $\begin{array}{c}\text { Frequência } \\
\text { secundária } \\
\text { ou auxiliar }\end{array}$ & $\begin{array}{c}\text { Ano de } \\
\text { primeiro } \\
\text { e último } \\
\text { registro }\end{array}$ & $\begin{array}{c}\text { Prováveis } \\
\text { Anos totais de } \\
\text { atividade }\end{array}$ \\
\hline G. T. Prance & 73 & 3 & $1964-1985$ & 21 \\
\hline J. Murça Pires & 46 & 5 & $1936-1987$ & 51 \\
\hline C. A. Cid & 26 & 9 & $1979-1991$ & 12 \\
\hline Ricardo de Lemos Fróes & 21 & 1 & $1932-1980$ & 48 \\
\hline Nilo T. Silva & 21 & 14 & $1936-1987$ & 51 \\
\hline N. A. Rosa & 21 & 26 & $1977-1992$ & 15 \\
\hline D. C. Daly & 21 & 5 & $1980-2001$ & 21 \\
\hline A. Ducke & 20 & - & $1903-1943$ & 40 \\
\hline B. A. Krukkof & 19 & 3 & $1933-1936$ & 3 \\
\hline G. A. Black & 17 & 7 & $1945-1994$ & 49 \\
\hline
\end{tabular}

Fonte: Herbário do NYBG, 2009.

Confirma-se a longa atuação de alguns destes botânicos durante muitos anos envolvidos com a atividade, metade deles com 40 anos ou mais de intenso trabalho no território amazônico, mesmo se considerando que parte de suas performances deva-se creditar às equipes que formaram e à regularidade do trabalho efetuado. A exceção é B. A. Krukkof ${ }^{8}$, que liderou expedições importantes na década de 30 do século passado, ao que tudo indica, com eficácia comprovada ao se incluir entre os dez mais performantes.

Como auxiliares, alguns dos nomes dos principais se repetem. Alguns deles se destacam por nunca terem assumido a liderança como coletores principais, como é o caso do que encabeça a lista, J. F. Ramos, com 79 participações, seguido de C. D. A. da Mota, com 44 ocorrências; O. P. Monteiro, com 31 e R. P. Bahia,

8 Boris Alexander Krukoff (1898-1983) foi consultor sobre florestas e botânica econômica da United States Rubber Company, Chicle Company e Merck Company. Fez numerosas expedições para a América do Sul e África entre 1929 e 1955, quando coletou material botânico e espécimes madeireiros. Ocupou a posição de Curador Honorário do New York Botanical Garden e consultor botânico na Merck Sharp e Dohme Research Laboratory. Tinha especial interesse em árvores gomíferas e fontes botânicas silvestres para drogas (Disponível em: <http://library.nybg.org/finding_guide/archv/krukoff_rg4f.html>. Acesso em: 7 abr. 2009). 
com 30. Entre os que aparecem como secundários, tendo registros também como principais, encontram-se C. Rosário/C. S. Rosário, apresentando 45 participações como auxiliar, enquanto aparece uma única vez como principal, do mesmo jeito que Bruce Walker Nelson, com 29 como auxiliar e 1 como principal. Segue-se a lista com W. C. Steward, apresentando 28 ocorrências como auxiliar e 3 como principal. N. A. Rosa, já citado com a participação liderando equipes, aparece 26 vezes como auxiliar. Completando os 10 mais representativos em coletas como auxiliares, aparecem L. G. Farias e M. R. dos Santos, com 21 e 20 coletas, respectivamente, como se pode confirmar na Tabela 2.

Tabela 2. Frequência dos 10 coletores secundários mais frequentes.

\begin{tabular}{l|c|c|c|c}
\hline \multicolumn{1}{c|}{ Coletor } & $\begin{array}{c}\text { Frequência } \\
\text { como primeiro } \\
\text { nome }\end{array}$ & $\begin{array}{c}\text { Frequência } \\
\text { secundária } \\
\text { ou auxiliar }\end{array}$ & $\begin{array}{c}\text { Ano de primeiro } \\
\text { e último registro }\end{array}$ & $\begin{array}{c}\text { Prováveis } \\
\text { Anos totais } \\
\text { de atividade }\end{array}$ \\
\hline J. F. Ramos & 1 & 79 & $1966-1983 / 1991$ & 17 a 25 \\
\hline C. Rosário/ C. S. Rosário & & 45 & $1978-1993$ & 15 \\
\hline C. D. A. Da Mota & & 31 & $1979-1986$ & 7 \\
\hline O. P. Monteiro & 1 & 30 & $1966-1983$ & 17 \\
\hline R. P. Bahia & 3 & 29 & $1977-1984$ & 7 \\
\hline B. Walker Nelson & 21 & 26 & $1967-1983$ & 19 \\
\hline W. C. Steward & & 21 & $1977-1992$ & 16 \\
\hline N. A. Rosa & & 20 & $1967-1980$ & 13 \\
\hline L. G. Farias & & & & 4 \\
\hline M. R. dos Santos & & & & \\
\hline
\end{tabular}

Fonte: NYBG, 2009.

Das Tabelas1 e 2, deve-se levar em conta a demonstração da mobilização no processo de coleta e organização das exsicatas, envolvendo um elevado número de pessoas habilitadas e que se tornaram fiéis a este esforço, atravessando décadas em atividade. Para ilustrar o aspecto da longevidade na atividade de coleta, J. F. Ramos aparece com o primeiro registro na equipe em 1966, e o último em 1983, cobrindo, portanto, apenas consideradas coletas de Verbenáceas, 17 anos de trabalho, desenvolvidos principalmente no estado do Amazonas, mas também, em menor intensidade, em Rondônia, Roraima, Acre e Pará. Existe uma ficha com informação em que as mesmas iniciais aparecem indicando ter ele feito uma determinação de espécie em 1991. Confirmando se tratar da mesma pessoa, esta cobertura vai para 25 anos de trabalho na área. O mesmo ocorre com C. S. Rosário, cujos registros cobrem de 1978 a 1993, dando conta de um engajamento de 15 anos de serviços prestados à Botânica. Dos dez listados como mais performantes, o que aparece com menos tempo de trabalho dedicado à coleta de Verbenáceas é M. R. Santos, com 4 anos, o que demonstra ter sido muito intenso o seu período de contribuição. 
Esse contingente e prática serviram de base para a formação de muitos botânicos brasileiros e americanos, em particular, mas também de outros países do mundo. Dos que adquiriram notoriedade no campo científico, pode-se encontrar dados biográficos com relativa facilidade por conta dos registros nas edições de jornais científicos e curriculuns disponíveis nas suas respectivas instituições de atuação, principalmente em se tratando de personalidades reconhecidas na Botânica Internacional ${ }^{9}$. Os de atuação internacional e formalização em cadastro no Index Herbariorum permitem acesso às suas contribuições, enquanto outros carecem de maior tratamento do que possam ter sido suas efetivas participações na construção do acervo e de uma leitura possível sobre as Verbenáceas na Amazônia. Outros, em particular os funcionários e auxiliares, em que pese se deva reconhecer toda a efetiva contribuição registrada, pouco ou nada se poderá encontrar, em função de seus enquadramentos subordinados. Este poderia ser um objeto efetivo de pesquisa histórica e antropológica a ser desenvolvido, montando-se biografias, por exemplo, o que poderá servir como registro histórico deste esforço de compreensão da biodiversidade.

Quando se analisa os dados da frequência das coletas por unidades da federação, verifica-se que 65\% das coletas foram feitas nos estados do Pará e Amazonas, em todo o período de 1819 a 2002 (Tabela 3). Deve-se lembrar da presença e atuação dos naturalistas desde o período colonial e de instituições de pesquisa nestes estados, em particular a do Museu Paraense Emílio Goeldi e do Instituto Agronômico do Norte, este transformado e absorvido pelas estruturas que resultaram na Empresa Brasileira de Pesquisa Agropecuária, a Embrapa.

A ação continuada do procedimento de coleta ao longo do período, ainda que com os altos e baixos que o gráfico ilustra, é um dos elementos explicativos de tal desempenho. Outro elemento que deve ser considerado na análise da incidência de coletas mais numerosas nestes estados é a sua facilidade de acesso pelos rios e da colonização que se fez justamente a partir dos cursos d'água. Para efeito de melhor compreensão do ambiente nos primórdios destes registros, há que se levar em conta que floresta e cidade praticamente se encontravam com muito menos distância do que as que passaram a ser exploradas posteriormente. Foram encontradas coletas feitas no próprio campo das instituições de ensino e pesquisa, tanto quanto o registro de que este trabalho era feito nos arredores e proximidades dos centros urbanos, como se pode ver do registro feito por Martius e Spruce em Belém e Santarém.

A verdadeira floresta a que fez menção Martius, em Belém, pôde ser guardada no que é o Bosque Rodrigues Alves, sabendo-se que a sua fundação foi

9 Ver informações disponíveis no site: <http://www.prancefamily.co.uk/Sir\%20Ghillean\%20 Prance.html>. Acesso em: 02 abr. 2009. 
do início do século XX, em área que, se na época era fora dos marcos da urbe, encontra-se completamente urbanizada um século depois.

Tabela 3. Coletas feitas por Unidades da Federação entre 1819 e 2002.

\begin{tabular}{c|c|c}
\hline Unidade Federativa & Ocorrências & $\mathbf{\%}$ \\
\hline AC & 61 & 8 \\
\hline AM & 191 & 25 \\
\hline AP & 49 & 5 \\
\hline MA & 40 & 4 \\
\hline MT & 32 & 40 \\
\hline PA & 291 & 5 \\
\hline RO & 39 & 6 \\
\hline RR & 45 & 0 \\
\hline TO & 2 & 100 \\
\hline Total & 750 &
\end{tabular}

Fonte: Herbário do NYBG, 2009.

Nesta demonstração se evidenciam contribuições relativamente proporcionais dos outros estados da federação, com menor monta para o estado do Tocantins, com dificuldades na identificação das amostras nele coletadas por conta da forma de registro que nem sempre possibilitava identificar o município, principalmente antes da criação deste estado, em 1988. O processo de emancipação de estados e municípios no Brasil é um dos obstáculos a superar nas referências de localizações encontradas no herbário estudado.

Há sempre a possibilidade de checagem e correção de dados, como o que merece a ficha $\mathrm{n}^{\circ} 2138$, coletada por W. L. Balée, em 6 de abril de 1986, em que se faz referência ao estado do Maranhão, mas em coleta feita no "Município de Altamira, Igarapé Ipixuna, affluent of Rio Xingu,; 4 49' S; $52^{\circ} 31^{\prime}$ W. $5 \mathrm{~km} \mathrm{~S}$ of settlement, Araweté Indian Reserve. - Terra firme forest. - Small tree, cm DBH: 12, red fruits". Esta área é, como se verifica do próprio registro, no estado do Pará.

Quanto às instituições que se envolveram no processo que permitiu a montagem da coleção, elas são oriundas, em sua maioria, do Brasil e dos Estados Unidos. Do total de 53, as brasileiras são em número de 30 e as americanas 18, as outras sendo da Inglaterra (2) e Japão (1). De duas restantes, não foram identificadas as origens. No caso das instituições brasileiras, o recurso financeiro mais frequente para apoiar as expedições foi do governo federal, através do Conselho Nacional de Desenvolvimento Científico e Tecnológico (CNPq), do qual eram canalizados recursos, principalmente para o Museu Paraense Emílio Goeldi (MPEG) e Instituto Nacional de Pesquisas da Amazônia (INPA) e Embrapa, nas suas versões históricas: Instituto Agronômico do Norte (IAN), Instituto de Pesquisa e Experimentação 
Agropecuária do Norte (IPEAN), e Centro de Pesquisa Agropecuária do Trópico Úmido (CPATU). Além dos centros localizados na região, ocorre o registro do Centro Nacional de Estudos Genéticos (Cenargen), do Distrito Federal. A atuação destes organismos se deu através de associações feitas por convênios, nos quais se formavam equipes para o trabalho realizado em expedições financiadas com recursos nacionais e internacionais.

O Ministério da Agricultura cumpre papel semelhante, fornecendo apoio às estruturas de seus institutos de pesquisa, tais quais o IAN, IPEAN e CPATU, depois Empresa Brasileira de Pesquisa Agropecuária. Muitas outras organizações compõem o leque de caudatários dos recursos do CNPq e Ministério da Agricultura, estruturando muitas formas de associação tanto com organismos públicos como privados. Entre os orgãos governamentais estão presentes, além dos listados acima, as Universidades Federal do Paraná, de Brasília, Estadual de Feira de Santana, de São Paulo, do Paraná e do Acre. Outros organismos que financiam e apoiam estas atividades são a Comissão Rondon, o Instituto Brasileiro de Geografia e Estatistica (FIBGE), Fundações de Apoio à Pesquisa das Universidades do Pará e Acre, Jardim Botânico do Rio de Janeiro, Instituto Brasileiro de Desenvolvimento Florestal (Ibama), Instituto de Botânica de São Paulo, Ministério das Minas e Energia, Museu Nacional do Rio de Janeiro e a Prefeitura Municipal de Curitiba. O apoio desta última deve-se ao fato de possuir e administrar o Jardim Botânico de Curitiba, que conta com um herbário (MBM) estruturado a partir do trabalho e da coleção do botânico Gerdt Hatschbach, que coletou mais de 100 mil números e ainda continua na ativa.

Das instituições estrangeiras, a parceira mais frequente é a National Science Foundation, que financia a atividade do New York Botanical Garden, associado com as diversas instituições de pesquisa e ensino no Brasil. Tem-se o registro de financiamento dos trabalhos de campo bancados por fundações ligadas ao NYBG (Rockfeller Foundation Found for Photographing Type Specimens, Marshal Field Jr Foundation, Edward Jobn Noble Foundation) ou a outras instituições como o Smithsonian Institute. Ocorrem ainda associações com instituições não governamentais e/ou privadas, a exemplo da Jari Comércio e Indústria, de propriedade do empresário americano Daniel Ludwig à época das coletas identificadas, a Exxon Foundation, multinacional identificada pelo forte capital americano. Os outros registros são do Latin American Natural History Museum, Museum of Natural History, Mulford Biological Exploration of the Amason Basin, NY Zoological Society, Royal Society-NYBG e United States Department of Agriculture.

A presença das Universidades Americanas se faz revelar pelos financiamentos da University of Florida e University of California. Curiosos são dois registros de 
financiamento pelo United States Army Edgewood Arsenal. A curiosidade aumenta se se considerar que os registros ocorrem nos dias 13/08/1964 e 30/10/1965, em pleno período inicial do governo militar, quando o clima no país era de muita instabilidade política. Da Inglaterra, os registros são do Overseas Development Administration e da Royal Society Geographic. Do Japão, a entidade registrada é o Oomoto Kameyama Botanical Garden, localizado em Kyoto.

Quanto à amplitude das instituições e pesquisadores envolvidos, vai além dos diretamente comprometidos com a coleta, mas com os receptores das amostras, aumentando o raio de beneficiários. Algumas fichas indicam o destino das duplicatas, em geral três diferentes instituições de diferentes países. $\mathrm{Na}$ ficha do NYBG e INPA aparecem listadas no rodapé as siglas de 19 herbários que deveriam ou poderiam ter sido caudatários das duplicatas. Em algumas delas estão riscadas algumas siglas, dando a entender que não receberam as duplicatas (ver por exemplo o n. 19703, coletada por Berg, Bisby e Monteiro, no rio Solimões no estado do Amazonas, em 23 de agosto de 1973). Nos casos em que não havia pistas indicando para onde foram remetidos os exemplares, foi considerado apenas o exemplar consultado no NYBG, sabendo-se que os parceiros no processo de coleta devem ter outras duplicatas.

Os beneficiários de todo este esforço são certamente mais amplos do que dão conta os registros. Isto significa que a abrangência da distribuição pode ser maior do que a constatada nesta análise. A dedução é pelo fato de que o próprio NYBG possui exsicatas vindas de herbários diversos, em praticamente todos os continentes, tendo as aquisições se dado por compra, doação de outros herbários ou particulares, ou por força dos acordos e convênios realizados por ocasião das montagens dos projetos e expedições exploratórias.

A localização das amostras pode sugerir o apoio de outras instituições ou empresas não necessariamente implicadas nos Programas, como é o caso da ficha que indica uma amostra sem número ter sido coletada por José Maria, no terreno da FCAP (Faculdade de Ciências Agrárias do Pará), em 4 de novembro de 1979 ou a de $n^{\circ} .843$, feita na sede da mineração, por L. O. A Teixeira et al.), em 28 de maio de 1982, sob os auspícios do Instituto Nacional de Pesquisa da Amazônia (INPA). No caso da primeira ficha, pode-se observar também que o nome do coletor não está completo, registrado apenas os dois prenomes.

$\mathrm{Na}$ lista de herbários receptores das duplicatas coletadas, enumeram-se os 35 que se encontram no Quadro 1, agrupando-os por país. Verifica-se que as instituições receptoras são de 14 países: Alemanha (2), Argentina (1), Áustria (1), Brasil (13), Colômbia (1), Dinamarca (1), Escócia (1), Estados Unidos (8), França (1), Inglaterra (1), Holanda (1), Suécia (1), Suíça (2) e Venezuela (1). 
A participação dos Estados Unidos se efetivou através das universidades da Flórida e Michigan, dos Jardins Botânicos localizados em New York, Missouri, Illinois, Chicago e Massachussets, assim como o Smithsonian Museum de Washington. Destaca-se, evidentemente, a importância do New York Botanical Garden, que serviu de ponto de partida para este estudo e pela contribuição que tem dado para a formação de botânicos e das coleções em todo o mundo.

Quadro 1. Herbários receptores das coletas de Verbenáceas na Amazônia.

\begin{tabular}{|c|c|c|c|c|}
\hline $\mathbf{N}^{\circ}$ & Sigla & Herbário/Instituição receptora & Cidade/Estado & País \\
\hline 01 & CTES & Instituto de Botánica del Nordeste & Corrientes & Argentina \\
\hline 02 & $\mathrm{E}$ & Royal Botanic Garden Edinburgh & Edingburg & Escócia \\
\hline 03 & $\mathrm{~K}$ & Royal Botanic Gardens & Kew & Inglaterra \\
\hline 04 & MBM & Museu Botânico Municipal & Curitiba/Paraná & Brasil \\
\hline 05 & NY & New York Botanical Garden & BronxNew Iork & EUA \\
\hline 06 & S & $\begin{array}{l}\text { Swedish Museum of Natural } \\
\text { History }\end{array}$ & Estocolmo & Suécia \\
\hline 07 & $\mathrm{U}$ & National Herbarium Nederland & Leiden & Holanda \\
\hline 08 & UFMT & $\begin{array}{l}\text { Universidade Federal de Mato } \\
\text { Grosso }\end{array}$ & Cuiaba/Mato Grosso & Brasil \\
\hline 09 & Z & Universität Zürich & Zurich & Suíça \\
\hline 10 & A & $\begin{array}{l}\text { Universidade Estadual de Feira de } \\
\text { Santana }\end{array}$ & Feira de Santana/Bahia & Brasil \\
\hline 11 & B & $\begin{array}{l}\text { Arnold Arboretum Harvard } \\
\text { University }\end{array}$ & Cambridge/Massachusetts & EUA \\
\hline 12 & C & $\begin{array}{l}\text { Botanischer Garten und } \\
\text { Botanisches Museum Berlin- } \\
\text { Dahlem, Zentraleinrichtung der } \\
\text { Freien Univesität Berlin } \\
\end{array}$ & Berlim & Alemanha \\
\hline 13 & $\mathrm{COL}$ & University of Copenhagen & Copenhagen & Dinamarca \\
\hline 14 & ESA & Universidad Nacional de Colombia & D.C.Bogotá & Colômbia \\
\hline 15 & $\mathrm{~F}$ & $\begin{array}{l}\text { Herbarium Botany Department of } \\
\text { Field Museum of Natural History }\end{array}$ & Chicago & EUA \\
\hline 16 & G & Field Museum of History Natural & Chicago/Ilinois & EUA \\
\hline 17 & HUEFS & $\begin{array}{l}\text { Conservatoire et Jardin botaniques } \\
\text { de la Ville de Genève }\end{array}$ & Genève & Suíça \\
\hline 18 & IAN & Embrapa Amazônia Oriental & Belém/Pará & Brasil \\
\hline 19 & INPA & $\begin{array}{l}\text { Instituto Nacional de Pesquisas da } \\
\text { Amazônia }\end{array}$ & Manaus/Amazonas & Brasil \\
\hline 20 & $\mathrm{M}$ & $\begin{array}{l}\text { Botanische Staatssammlung } \\
\text { München }\end{array}$ & Munique & Alemanha \\
\hline $\mathbf{N}^{\circ}$ & Sigla & Herbário/Instituição receptora & Cidade/Estado & País \\
\hline 21 & MG & Museu Paraense Emílio Goeldi & Belém/Pará & Brasil \\
\hline 22 & $\mathrm{MICH}$ & University of Michigan & Ann Arbor/Michigan & EUA \\
\hline 23 & $\mathrm{MO}$ & Missouri Botanical Garden & Saint Louis/Missouri & EUA \\
\hline 24 & $\mathrm{P}$ & $\begin{array}{l}\text { Muséum National d'Histoire } \\
\text { Naturelle } \\
\end{array}$ & Paris & França \\
\hline 25 & $\mathrm{R}$ & $\begin{array}{l}\text { Universidade Federal do Rio de } \\
\text { Janeiro }\end{array}$ & $\begin{array}{l}\text { Rio de Janeiro/Rio de } \\
\text { Janeiro }\end{array}$ & Brasil \\
\hline
\end{tabular}




\begin{tabular}{|l|l|l|l|l|}
\hline 26 & RB & Jardim Botânico do Rio de Janeiro & $\begin{array}{l}\text { Rio de Janeiro/Rio de } \\
\text { Janeiro }\end{array}$ & Brasil \\
\hline 27 & SP & Instituto de Botânica & São Paulo/São Paulo & Brasil \\
\hline 28 & SPF & Universidade de São Paulo & São Paulo/São Paulo & Brasil \\
\hline 29 & UB & Universidade de Brasília & Brasilia/Distrito Federal & Brasil \\
\hline 30 & UFAC & Universidade Federal do Acre & Rio Branco/Acre & Brasil \\
\hline 31 & UFL & Universidade da Flórida & Gainisville/Flória & EUA \\
\hline 32 & UFMG & $\begin{array}{l}\text { Universidade Federal de Minas } \\
\text { Gerais }\end{array}$ & $\begin{array}{l}\text { Belo Horizonte/Minas } \\
\text { Gerais }\end{array}$ & Basil \\
\hline 33 & US & $\begin{array}{l}\text { Smithsonian Institution } \\
\text { Cashington/District of }\end{array}$ & EUA \\
\hline 34 & VEN & $\begin{array}{l}\text { Fundación Instituto Botánico de } \\
\text { Venezuela Dr. Tobías Lasser }\end{array}$ & Caracas & Venezuela \\
\hline 35 & W & Naturhistorisches Museum Wien & Viena & Áustria \\
\hline
\end{tabular}

Fonte: Herbário do NYBG, 2009.

\section{USOS REGISTRADOS NOS RÓTULOS E NOMES POPULARES}

As informações contidas nos rótulos podem ainda indicar os usos que as plantas podem oferecer. É uma estratégia usada ainda em tempos mais recentes (VON REIS; LIPP Jr., 1982), pois os coletores podem ter inserido nos rótulos informações sobre os diferentes usos dessas plantas. A existência desse tipo de informação está muito ligada aos objetivos em que os programas e/ou projetos que permitiram essas coletas estão inseridos, por exemplo, na área de Botânica Econômica ou Etnobotânica, ou ainda, de acordo com o interesse do coletor e sua área de especialidade. As demais coletas, com cunho quase exclusivamente taxonômico, florístico ou ecológico, geralmente não apresentam qualquer informação sobre esse aspecto.

Para o coletor colocar no rótulo determinado uso (ou usos) das plantas, ele pode ter utilizado informação que ele próprio conhece, a partir de sua própria experiência ou lido em alguma literatura. Pode, ainda, obter informações de outros, diretamente. Para essa última alternativa ocorrer, a pessoa que deu a informação pode estar ou não junto com o coletor no momento da coleta. Se estiver junto, é possível que seja seu auxiliar (que pode conhecer os usos das plantas da região de coleta) ou mesmo ser um membro de alguma comunidade na região onde a coleta está ocorrendo, acompanhando ou participando da coleta. Assim, o coletor pode indagar a este se conhece algum uso local para a planta coletada.

Em coletas etnobotânicas, é comum a presença de membros das comunidades locais, em especial como um informante privilegiado, pois sua experiência e vida na região fizeram-no bom conhecedor da vegetação local e 
suas potencialidades de uso. Assim, o coletor (ou o pesquisador que coordena o trabalho), da área etnobotânica, usualmente insere essas informações obtidas junto aos membros locais.

Convém reforçar que, em função da legislação brasileira acerca do acesso de recursos genéticos e informações associadas, que procura proteger esses recursos, muitos pesquisadores, mesmo de áreas de Etnobotânica ou Botânica Econômica, não coletam esses dados ou não os expressam nos rótulos, para evitar algum tipo de problema relacionado ao direito de propriedade intelectual das informações, visto que não somente recurso genético é importante, como também as informações associadas a esse recurso, que podem vir de comunidades tradicionais e/ ou indígenas. Essa situação pode explicar a pequena quantidade de rótulos contendo informações sobre o uso das plantas, em especial as coletadas em épocas mais recentes.

No presente trabalho, da relação total das exsicatas fotografadas, apenas em 18 exsicatas foram encontradas informações acerca do uso das plantas. Dessas, 14 foram encontradas em rótulos de coletas realizadas entre 1932 e 1986, e 4 de coletas após 1993.

Significativa é a constatação de que justamente após a Conferência Rio92, onde as nações em desenvolvimento discutiram e aprovaram em assembleias globais recomendações sobre a proteção dos recursos genéticos e informações associadas, e levantando a bandeira da autonomia de gestão desses recursos pelos países que os detêm, o número de exsicatas que poderiam indicar informação obtida a partir das comunidades locais diminuiu consideravelmente. Anteriormente a esse evento mundial, tal preocupação não era ainda foco de discussões, ou mesmo nem existia, por isso as coletas eram feitas mais livremente, sem preocupações de ordem ética e/ou política, como acontece nos dias de hoje.

As categorias de uso observadas nos rótulos variaram, sendo encontradas: comestível, medicinal, uso como lenha e substituto de fumo. Nesta última categoria, duas exsicatas foram coletadas, ambas em Marechal Taumaturgo, Acre, em 1993, por D. C. Daly, para a planta Cytharexylum sp., espécie cultivada e que recebe o nome popular de "fumo-bravo", provavelmente devido ao uso, conforme citado no rótulo.

As coletas com indicação de uso das plantas nos rótulos foram realizadas tanto por brasileiros quanto por estrangeiros. Pode-se destacar a presença de etnobotânicos na lista dos coletores, como W. L. Balée, que trabalhou na Reserva Araweté, na região de Altamira, Pará, com os índios Tukano e que indicaram ser comestíveis os frutos de Citharexylum macrophyllum Poir, além do uso como lenha (provavelmente o caule e/ou ramos). Este mesmo etnobotânico, para outra coleta, 
desta vez de Amasonia sp., na mesma comunidade indígena, indicou: No reported use. Ou seja, ele estava buscando informações sobre o uso das plantas, e para esta espécie, os indígenas não indicaram nenhum.

As indicações de uso, bem como o restante das informações dos rótulos foram grafadas na língua do coletor principal, com exceção de três. Em duas delas, o coletor foi Manoel Barbosa da Silva, provavelmente pertencente ao Instituto Agronômico do Norte (IAN), que, em 1942, em Belém, coletou Lippia alba var. globiflora e Stachitarpheta em Belém, perto do Instituto Agronômico do Norte, em trabalho patrocinado pelo próprio IAN e constam as seguintes indicações: "Tea of leaves taken to countered effects of purgative" (para a primeira espécie) e "Root used for tea to cure dysentery" (para a segunda espécie). Numa observação mais atenta aos dois rótulos, é possível perceber que foram datilografadas nos Estados Unidos, provavelmente a partir de um rótulo preliminar (talvez em português), por um americano, uma vez que elas também fazem parte do acervo do Smithsonian Institution, do United States National Herbarium, conforme dá para denotar a partir de um fragmento de papel com essa indicação, acima do rótulo. Ou seja, as coletas foram feitas por um brasileiro, no Brasil, e posteriormente os rótulos foram digitados nos Estados Unidos.

Em exsicata coletada por J. Jangoux, no rio Curuá, no Pará, para o Projeto Flora Amazônica, financiado pelo CNPq, NSF (National Science Foundation, dos Estados Unidos), INPA, MPEG e NYBG, as informações do rótulo estão grafadas em português, provavelmente devido à destinação da coleta ou talvez pela presença de um cocoletor brasileiro, B. G. S. Ribeiro. Necessário checar a nacionalidade do primeiro coletor, porém é possível que o relatado aqui tenha ocorrido. Pode ainda ter ocorrido o fato de o material coletado ter sido processado no Brasil e o rótulo ter sido preenchido no mesmo país, como pode parecer, devido às características deste, datilografado em máquina elétrica da época (1981).

Há também uma situação inversa, ou seja, as informações estarem grafadas em inglês, com coletores brasileiros, como já dito anteriormente. Em coleta realizada por dois ilustres e importantes botânicos brasileiros, J. Murça Pires e Paulo B. Cavalcante, em 1962, no Amapá, para Lantana armata, todas as informações do rótulo estão escritas em inglês, com exceção do nome vernacular, que está em português ("camara"). Esta mesma dupla de botânicos também coletou, em 1966, Stachytarpheta australis, no Amapá, na região costeira, próximo ao rio Matapi e o rótulo também foi preenchido em inglês, com exceção do nome vernacular, "rinchao".

Nota-se, em ambos os casos, que os rótulos foram impressos em gráfica, deixando-se vazias as partes que deveriam ser completadas durante as coletas, desta forma, as informações sobre os ambientes e as características das plantas, dentre outras, foram completadas via máquina de datilografar, provavelmente por algum 
estrangeiro, já que não foram colocados os respectivos acentos em "camará" e "rinchão", se fossem grafados corretamente em português.

A palavra "camará" inclusive é originária da palavra tupi de mesma grafia, que é designação comum a diversas plantas das famílias Verbenáceas e Solanáceas, conforme Cunha (1998). Alguns dos primeiros viajantes que estiveram no Brasil, nos finais do século XVII, como o Padre Fernão Cardim e Gabriel Soares de Sousa, já se referiram a esta espécie com esta denominação.

Do total dos rótulos estudados, foram encontrados 45 que continham os nomes populares das plantas. Da mesma forma como ocorre com as informações sobre o uso das plantas coletadas, a origem da informação pode variar. Em coletas onde o coletor principal está acompanhado por membros brasileiros e mesmo em coletas onde aparece apenas um coletor estrangeiro, os nomes populares são grafados em português. Esse fato pode comprovar a participação de membros das comunidades das regiões onde essas coletas foram realizadas e que provavelmente deram essas informações sobre os nomes locais.

Há ainda dois casos em que os nomes populares foram grafados em língua indígena, nas coletas realizadas em comunidade indígena, como pode ser visto no rótulo de Amaz̧onia sp, coletado junto à Reserva Indígena Araweté, no Rio Xingu, Altamira, Pará, conhecida localmente pelo nome jatisithopanani, e Vitex triflora, coletado no Pará, junto aos índios Assurini, que dão o nome de kujuwa’ywa.

A existência de nomes populares diferentes para a mesma espécie é um fato comum, ou ainda espécies diferentes receberem o mesmo nome popular, pois reflete a diversidade cultural existente e a forma com que membros dessas diferentes culturas entendem e nomeiam os elementos da natureza. A dinâmica da nomenclatura popular deve levar isso em consideração e também a introdução e/ou contato com novos elementos culturais, alterando a situação anterior.

Lantana trifolia e Lantana armata receberam os nomes populares "cambará" e "camará", respectivamente, numa clara demonstração de semelhança fonética. A espécie L. camara, em coleta feita em Rio Branco, Acre, em 1978 e 1979, recebeu o nome de "chumbinho". Já em Xapuri, também no Acre, em 1994, na Reserva Extrativista Chico Mendes, município de Xapuri, o nome vernacular dado foi de "camará".

Da mesma forma, diferentes espécies de Vitex receberam nomes populares como: tarumã, piquia-rana, tarumão e mangaba, dependendo do local de coleta, bem como Stachytarpheta cayennensis recebeu nomes de: rinchão (em Belém, Pará), rincão (em Rio Branco, Acre), gervão (em Almeirim, Pará) e carrapichinho (em Tarauacá, Acre). Esses exemplos demonstram a diversidade cultural e a complexidade existente na denominação das plantas, mesmo estando todas localizadas na Amazônia brasileira. 


\section{ANTROPIZAÇÃO NOS REGISTROS DAS EXSICATAS}

O registro sobre as condições do ambiente em que foi encontrada a planta que originou a amostra é um dos pontos frequentes e recomendados nos procedimentos canônicos desta atividade, embora em épocas mais antigas, não tenha sido totalmente observado. Costumam oferecer pistas importantes sobre o processo de preservação ou degradação do solo, por informações pontuais, mas que induzem a interpretações densas. Habitat in silves verum Amazonicum é a frase que se pode ler na exsicata coletada por Martius no estado do Pará, em setembro de 1819, um mês após sua chegada àquela então Província, depois de extenso percurso, passando por outros ambientes ao longo de quase três anos de marcha, conforme se pode depreender do croquis do roteiro que ilustra a viagem que fundamentou seu exaustivo e reconhecido trabalho.

Carl Friedrich Philipp von Martius, alemão de nascimento em Herlangen no Sul da Baviera, em 1794, falecido em Munique em 13 de dezembro de 1868, veio ao Brasil juntamente com seu conterrâneo Johann Baptiste von Spix (17811826), fazendo parte da comitiva científica que acompanhou a Arquiduquesa austríaca Leopoldina de Habsburgo, que viria a ser a primeira Imperatriz do Brasil (1822-1826) e Rainha consorte de Portugal por seis dias (1826), por laços de matrimônio com D. Pedro I. Empreendendo excursão de natureza científica pelo país entre 1817 e 1820, os naturalistas coletaram uma das mais importantes amostras de informações botânicas, geológicas, zoológicas e antropológicas de toda a história brasileira. Este material orientaria praticamente toda a vida dos cientistas, servindo de referência para muitos dos que viriam a compor os quadros da botânica internacional.

Merece destaque o naufrágio que ele sofreu, no dia 18 de setembro de 1819, no rio Amazonas, na Villa de Santarém (atual Santarém, no Pará). Tendo sido salvo "por misericórdia divina do furor das ondas do Amazonas", mandou confeccionar um crucifixo, que foi doado em 1846, para a Igreja de Nossa Senhora da Conceição, naquela cidade, onde permanece até os dias de hoje. Após sucessivas reformas, essa igreja, erigida em 1761, atual Catedral de Santarém, mantém essa imagem de bronze com suporte em uma cruz feita de caule de acariquara, dandolhe uma característica original.

Merece atenção no registro daquela exsicata os termos em latim (Habitat in silves verum Amazonicum. Provincie paraensis.), dando conta de se tratar de um ambiente diferenciado dos outros que havia percorrido até então.

O registro de Martius, além de nitidamente geográfico, acena para o fato de estar coletando material em floresta primária, sentimento e percepção que 
firma certamente ainda sob o impacto da exuberância da floresta com a qual teria se deparado, após ter percorrido outros biomas, de tal forma que essa expedição orientaria praticamente todo o curso de sua vida profissional.

A estrutura de anotação (gênero, espécie, localidade, província, coletor, data), lida e feita comparação entre os feitos ao longo da série, dá uma ideia da crescente ocupação da região por populações dispersas ou concentradas, atividades rurais produtivas (sítios, fazendas, assentamentos), e extrativas (seringais, castanhais, mineração), infraestrutura (estradas, acampamentos, alojamentos), conforme se demonstra ao longo desta seção.

Quando Martius adjetiva a floresta como verdadeira, sugere estar diante de mata primária, evocando o questionamento feito por Diegues em O Mito Moderno da Natureza Intocada (2008). Outra interpretação possível é de que a floresta Amazônica se manifesta com a força que não deixa dúvida sobre sua identidade. A ancestral presença de numerosa população indígena, com seus métodos de cultivo e exploração da mata promoveu alterações, como o adensamento de espécies úteis como a castanha-do-pará, pupunha e o cupuaçu, ou o raleamento de áreas para incursões de caça, ou ainda o desmatamento para plantio de roça de mandioca e milho, o que deve ter feito impacto significativo, embora recuperado pela prática do pousio. Deve-se levar em consideração igualmente o impacto destas populações em termos de permanência e itinerância, relação com os recursos utilizados na construção de habitações e utensílios necessários à produção e reprodução de seus estilos de vida. Ainda sobre os trabalhos de Martius, que se prolongaram por muitos anos depois da coleta, com a montagem, análise do material coletado e registros, verifica-se uma delas com data de 1839, suscitando a dúvida sobre sua autoria. Ora, se Martius a coletou entre 1817 e 1820, porque teria datado de 1839? Nesta mesma coleta, a referência à Cuiabá é feita, não se sabendo exatamente o que se pretendia informar (In. Serra a cima propre Cuyabâ).

Outra notação que estimula a imaginação é a que utiliza os termos que dão ideia de proximidade ou distância de povoações importantes. In vicinibus Santarém, feito por Spruce, em três exsicatas de $1850^{10}$, sugere que os arredores do povoado teriam sido os locais das coletas. Ali, igualmente, a proximidade da população já radicada sugere a evocação de área antropizada e praticamente integrada ou sob controle dos colonizadores. Deve-se levar em conta de que o trabalho do taxonomista de flora tão rica estava praticamente sendo iniciado, o que lhes permitia coletar material inédito, original, nos arredores das povoações, tanto

10 Todas feitas em Santarém, nenhuma delas numeradas. Uma feita de Amasonia lasiocaulos Mart, em janeiro, outra de Aegiphyla arboreum Vahl, em abril, e a terceira de Vitex cymosa Benth, em julho de 1850. 
quanto nos lugares mais distantes. Tratava-se praticamente de uma varredura de todo o universo do bioma, fosse ele perto ou longe das aglomerações humanas.

O mesmo ocorre quando se utiliza o termo inglês (near), quando se trata de referenciar uma povoação como Belém, Santarém, São Gabriel da Cachoeira, Bragança, nestes casos servindo tanto de referência geográfica quanto de nível de interação humana. Existem citações de proximidade com a confluência de rios, proximidade de praias, dos prédios das instituições onde os pesquisadores estavam alojados ou dos acampamentos montados para abrigar a expedição. A ideia de proximidade pode significar igualmente o escrúpulo dos exploradores em manter a coesão do grupo e resguadar-se de ataques de animais selvagens ou de aborígenes, o que no caso era possível de acontecer.

Deve-se ler com atenção este material uma vez que termos descritivos de paisagem são carregados de significados antrópicos. "Low capoeira”, por exemplo, pode ser entendida como área secundária em processo de recuperação, ou ainda em processo de uso como fonte de madeira, mel, pequenos animais silvestres, pasto de animais de porte grande, médio e pequeno, principalmente se localizado à margem de estradas de acesso, como de fato foi feito registro ${ }^{11}$. Verifica-se que a preocupação em uma tradução apropriada levou os coletores, botânicos ou não, a adotarem termos regionais como terra firme, caatinga, capoeira, igapó, demonstrando interação com personagens locais ou nativos. Este tipo de registro não aparece nas exsicatas dos pioneiros, em que se primava por uma linguagem culta, rigorosa, em latim, como a da Aegiphyla coletada em Boim, no rio Tapajós, estado do Pará: "silva secundaria non innundabili" foi o ambiente encontrado em 7 de abril de 1924, por J. G. Kuhlmann.

João Murça Pires e G. A. Black aparecem com os primeiros registros de termos regionais em 13 de abril de 1947. Na coleta no 1499 de exemplar de Amazonia lasiocaulos, em Curuçá, no estado do Pará, na "Estrada do Abade, capoeira alta”, inauguram na série de Verbenáceas o uso de termos do jargão brasileiro. Em material de autoria de equipe comandada por B. W. de Albuquerque, não datado na coleta, mas classificado em 1980 por Moldenke, indica que a Lantana trifoliapluripedunculata Mold. Foi encontrada em "Rio Branco - Porto Velho Highway, Km 22; Quinoá. Low capoeira, terra firme" em que se misturam termos em inglês e português. Ainda que se possam fazer críticas quanto ao rigor da língua no registro, o fundamental é a riqueza de informações que vem ali, indicando a presença de uma estrada, o ponto em que a coleta foi feita, a condição de drenagem do terreno e o estágio em que se encontra a vegetação.

11 Coleta de Lantana trifólia- pluripedunculata Mold. Det. H. N. Moldenke, 1980. nº. 1280, sem data, feita no Estado do Acre por B. W. de Albuquerque; C. D. A. da Mota; J. G. De Oliveira. 1280 em que se lê: "Rio Branco - Porto Velho Highway, Km 22; Quinoá. Low capoeira, terra firme". 
A indefinição geográfica aparece em casos em que a fronteira era pouco conhecida do coletor, como no que se lê, no exemplar no. 9721, escrito por E. Ule: "Kletterstr., Seringal Auristella, rio Acre, 'Peru' (probably Brazil)". A anotação de dúvida indica não ter o coletor utilizado aparelho de precisão para identificar as coordenadas da área, tampouco ter utilizado conhecimento no local sobre a identificação mais elaborada, ainda que se tratasse de área de extração vegetal com presença humana sistematicamente supervisionada. O fato é que a área era identificada como Peru, com a possibilidade de erro sobre os limites com o Brasil.

Quanto ao que se refere à exatidão, os termos nem sempre ofereciam elevado grau de precisão, embora acidentes geográficos ou a noção de referência em relação a alguns deles estejam frequentemente assinalados e sejam por si mesmos valiosas: "Ad oram septentrionalem fum. Amazonum ad ostium Rio Negro." Por vezes, mesmo o termo latino dá ideia do esforço de tradução literal do sentido regional, como no caso de "ostium" lembrando o termo "boca", muito utilizado popularmente em português para falar designar a desembocadura do rio ou de seu ponto de confluência com o principal ou, ainda, como entrada.

A indicação de frequência da planta na paisagem pode ter significados vários, desde o de ser sinalização de coleta para os fins a que o vegetal esteja servindo (medicinal, farmácia, construção de equipamentos), ou pela dizimação, por conta da implantação de estradas ou exploração mineral. Sua abundância pode ser compreendida por evidências que favoreçam a sua maior incidência. $\mathrm{O}$ primeiro caso pode ser ilustrado pela Vitex triflora Vahl coletada sob o ${ }^{\circ}$. 38398, por Richard S. Cowan, em 17 de novembro de 1954, na "Serra do Navio. Rio Amapari. Tree 8m. Calyx green, foliaceous. Corolla paler lavender with larger purple lobe. Infrequent in lowland forest along trail to Serra do Viado. (Wood sample). Heavely forested hills 70-300 m. alt." O segundo, pode ser demonstrado pela Vitex triffora Vahl, sob n ${ }^{\circ}$. 50466, encontrada por João Murça Pires, Rodrigues e Irvine, no Território do Amapá, em 24 de agosto de 1961: 'Small tree 2m high, $8 \mathrm{~cm}$ diam, calyx green, corolla blue, frequent in shadow of forest, about 5 hours above Rio Mururé., altitude $130 \mathrm{~m}, 01^{\circ} 24^{\prime} \mathrm{N}-51^{\circ} 57^{\prime} \mathrm{W}$ '.

A capoeira, qualquer que seja o seu porte, é reserva importante na cultura camponesa, podendo representar um valor efetivo, tanto do ponto de vista material quanto imaterial, como demonstrou Paulo Roberto Vieira, em sua Dissertação de Mestrado, intitulada "Florestas secundárias e comunidade: cotidiano de famílias camponesas em Jericó, Garrafão do Norte - Pará", defendida em 2005.

No caso da vegetação secundária, encontra-se frequentemente adjetivada como baixa (low), pequena (silvula secundaria que pode ser traduzida por pequena floresta secundária) ou branca (in silvula "caatinga"). No caso deste último termo,

12 Coleta de Vitex, sob o nº. 23763 feita por Adolpho Ducke, no estado do Amazonas, em $02 / 11 / 1932$. 
combinando latim e tupi guarani, tem-se, além do sincretismo linguístico, uma composição de floresta pequena expressa no diminutivo "silvula" combinado com a rarefação da vegetação, em "caatinga, literalmente com o significado de "mata branca", pelo aspecto que adquire.

Existem outros termos que deixam imaginar ou divagar como "silva secundaria sub radicibus"13". Qual o significado de "sub radicibus" neste caso? Trata-se de lianas? Ou de campo com presença de tocos após o primeiro uso de cultivo? Os cadernos de campo e relatórios dos naturalistas e botânicos merecem pesquisa para se verificar se existem ali pistas mais elaboradas sobre o que finalmente foi codificado nas restritas fichas das exsicatas.

É recorrente a menção à circunscrição dos centros de pesquisa e ensino como a Reserva Florestal Ducke e o Instituto Agronômico do Norte como áreas de coleta, com referências aos seus equipamentos infraestruturais (estradas, edifícios, acampamentos). Houve casos em que os alojamentos das expedições e das empresas serviram de base e de referência do local de coleta, principalmente quando próximos a este, ocorrendo, entretanto, citações de distâncias de quilômetros em relação a eles.

Nem sempre as estruturas referidas são importantes pela sua natureza, mas pelo que trazem de informações suplementares, como a "estrada para a serraria"14, em Marabá ou a "Estrada da Serraria", ${ }^{15}$ em Santarém, indicando a presença de usinas processadoras de madeira. Referência direta à Serraria em coleta feita nas terras da Jari Indústria e Comércio, em Monte Dourado ${ }^{16}$, dão conta da presença de igual equipamento e intensidade com que este recurso era utilizado.

Outra linha de abordagem poderia ser a de considerar as exsicatas no contexto mesmo em que foram produzidas, o que pode ser eficaz para o caso daquelas em que as indicações permitem uma interpretação apurada, de certa forma antecipada pelo registro feito. É o caso de exemplar no de Citharexylum poepigii Valp., coletada por N. T. Silva sob o n. 57802. Coletada em Belém, a ficha faz indicação de participação do NYBG e da Universidade de Brasília em expedição denominada "Exploration of New Brazilian Highways", demonstrando o levantamento sendo feito nos primórdios da abertura da Rodovia Belém-Brasília, precisamente em 3 de dezembro de 1963.

13 Coleta de Aegiphila integrifolia sob o n. 35663 feita por Adolpho Ducke, em Rio Branco, no estado do Acre, em 01/07/1937.

14 Aegiphila racemosa Vell. Colhida por M. G. Silva e R. Bahia sob o nº. 3048 na Serra dos Carajás, em 05/04/1977. Atualmente a área pertence ao município de Parauapebas.

15 Aegiphila racemosa Vell. Coletada por M. R. Santos, sob o n. 592, em Curuá Una, Santarém, em 27/01/1979.

16 Coleta de Amasonia "Mendoca"(está grafado certo, com as aspas e o M maiusculo?), feita por Emanoel Oliveira sob o no. 4469, Monte Dourado, estado do Pará, em 10/06/1968. 
Estes são alguns exemplos da riqueza encontrada neste material para uma compreensão das transformações promovidas pelo ser humano no bioma amazônico ao longo dos dois últimos séculos.

\section{CONCLUSÃO}

As exsicatas permitem, como se pode ver desta leitura da série de Verbenáceas coletada na Região Norte do Brasil, entre 1819 e 2002, compreender muito mais do que aspectos botânicos do material coletado. A percepção dos coletores sobre as transformações no meio ambiente ficam evidentes na linguagem que caracteriza o espaço, principalmente no que concerne à presença e à ação de grupos sociais na conformação do próprio campo botânico, em termos técnicos ou regionais que denunciam o impacto das atividades econômicas e sociais sobre o ambiente. Pode-se, portanto, concluir, pelas coletas, variando em ambientes com níveis de antropização diversos, desde o da mata primária preservada, passando pelos cultivos sendo realizados, até o de capoeiras e áreas de pousio-antigas e novas, revelando maior ou menor incidência das espécies. A tarefa a que se atribuíram os taxonomistas foi a de fazer uma cobertura completa do universo vegetal da região, ainda que se saiba do enorme potencial ainda existente para se levar a efeito o objetivo original.

Nota-se uma significativa perda na qualidade do material, pelo fato de não trazerem registrados os usos das plantas coletadas, o que deixa indagações como caminho aberto para novas investidas de pesquisa. Sabe-se do escrúpulo de muitos pesquisadores e instituições em relação à preservação da propriedade intelectual entre os nativos, o que, entretanto, pode ter sido registrado nos cadernos de campo dos coletores, ou publicados sobre outras formas de edição, cabendo esforço diferenciado para este tipo de informação.

$\mathrm{O}$ que se demonstra com este esforço de leitura das exsicatas em série temporal e espacial delimitada é a possibilidade de interpretação diferenciada daquela que normalmente se faz a partir deste material. De fato, o contexto em que a planta foi encontrada é muito mais do que uma informação sobre as características do vegetal, podendo ser elemento fundamental na percepção da apropriação histórica e antropológica do espaço. Para esta percepção, todas as disciplinas devem ser mobilizadas, uma vez que é efetivamente da transdisciplinaridade de que se está praticando quando da realização dos registros. 


\section{REFERÊNCIAS}

AYMARD, G.; CUELLO, N. Two new Species of Aegiphila (Verbenaceae) from Venezuela and Brazil. Novon, v. 14, p. 20-24, 2004.

CUNHA, A. G. Dicionário Histórico das Palavras Portuguesas de Origem Tupi: 1-357. São Paulo: Editora Melhoramentos, 1998.

DALY, D. C.; LISBOA, P. L. B. The Amazon, the Museu Goeldi, and the New York Botanical Garden. Boletim do Museu Paraense Emílio Goeldi. Série Botânica, v. 7, n. 2, p. 191-198, 1991.

DUCKE, A. Colheita de material botânico na Região Amazônica (Relatórios de 1929/30 e 1931/1933. Rio de Janeiro: Ministério da Agricultura/Departamento Nacional da Produção Vegetal/Instituto de Biologia Vegetal, 1934. Separata.

DUCKE, A. Colheita de material botânico na Região Amazônica (Relatório dos trabalhos realizados em 1935/1937. Rio de Janeiro: Ministério da Agricultura/ Departamento Nacional da Produção Vegetal/Instituto de Biologia Vegetal, 1938. Separata.

INDEX HERBARIORUM. Parte 1. New York: The New York Botanical Garden, 1990.

KURY, L. Viajantes naturalistas no Brasil oitocentista: experiencia, relato e imagem. História, Ciencias, Saúde-Manguinhos, v. 8, p. 863-880, 2001. Suplemento.

MADALENO, I. M. Arca de Noé Florida: Saberes e práticas medicinais ancestrais da América Latina. In: WORKSHOP PLANTAS MEDICINAIS E FITOTERAPÊUTICAS NOS TRÓPICOS. IICT /CCCM, 29, 30 e 31 de Outubro de 2008. Disponível em: <http://www2.iict.pt/archive/doc/I_Madaleno_ wrkshp_plts_medic.pdf $>$. Acesso em: 26 ago. 2011.

MANIA, L. F.; ASSIS, M. A. Processo de informatização do herbário rioclarense (HRCB) da Universidade Estadual Paulista (UNESP), Campos de Rio Claro, SP, e sua inclusão no sistema de rede. Revista Ciência em Extensão, v. 4, n. 1, p. 8-21, 2008.

THE NEW YORK BOTANICAL GARDEN; INTERNATIONAL ASSOCIATION FOR PLANT TAXONOMY. Index Herbariorum: A Global Directory of Public Herbaria and Associated Staff, 2009. Disponível em: <http:// sciweb.nybg.org/science2/IndexHerbariorum.asp>. Acesso em: 28 abr. 2009.

VON REIS, S. ; LIPP Jr., F. J. New plants sources for drugs and foods: 1-363. from The New York Botanical Garden. Cambridge: Harvard University Press, 1982. 